\title{
Anti-protein C antibodies and acquired protein C resistance in SLE: novel markers for thromboembolic events and disease activity?
}

RUNNING TITLE: anti-protein C antibodies in systemic lupus erythematosus

Giuseppe A. Ramirez ${ }^{1,2,3}$ MD, lan Mackie ${ }^{4}$ BSc, PhD, FRCPath, Susanna Nallamilli ${ }^{4,5} \mathrm{MBCHB}$, BSC, DTM\&H, Tatiana Pires ${ }^{1,2,6}$ MD, Rachel Moll ${ }^{4,5}$ BMBCh, MRCP, FRCPath, Charis Pericleous $^{1,2}$ BSc, MSc, PhD , David A. Isenberg ${ }^{1,2}$ MBBS, MD, FRCP, FAMS, Hannah Cohen ${ }^{4,5}$ MBChB, MD, FRCP, FRCPath, Maria Efthymiou ${ }^{4}$ BSc, MSc, PhD

${ }^{1}$ Centre for Rheumatology, Division of Medicine, University College London, London, UK ${ }^{2}$ Department of Rheumatology, University College London Hospitals NHS Foundation Trust, London, UK

${ }^{3}$ Università Vita-Salute San Raffaele, Milan, Italy

${ }^{4}$ Haemostasis Research Unit, Department of Haematology, University College London, London, UK

${ }^{5}$ Department of Haematology, University College London Hospitals NHS Foundation Trust, London, UK

${ }^{6}$ Serviço de Medicina 1, Hospital de Santo André, Centro Hospitalar de Leiria, Leiria, Portugal

\section{Corresponding author:}

Dr Maria Efthymiou

Haemostasis Research Unit,

Department of Haematology,

University College London

London WC1E 6HX

UK

Email: m.efthymiou@ucl.ac.uk 


\section{Objectives}

Risk factors for thromboembolism in systemic lupus erythematosus (SLE) are poorly understood. We hypothesised a possible role for protein $\mathrm{C}$, based on its dual activity in inflammation and haemostasis and on the evidence of an association between acquired activated protein C (APC) resistance $(A P C R)$ and high-avidity anti-protein $C$ antibodies (anti-PC) with a severe thrombotic phenotype in venous thrombosis antiphospholipid syndrome (APS) patients.

Methods. In a cross-sectional study of 156 SLE patients the presence and avidity of IgG anti-PC was established by in house-ELISA, and APCR to exogenous recombinant human APC (rhAPC) and Protac $\AA$ (which activates endogenous protein $\mathrm{C}$ ) was assessed by thrombin generation-based assays. Associations with antiphospholipid antibody (aPL) profile, thrombotic history and disease activity (British Isles Lupus Assessment Group 2004 index, BILAG, and SLE disease activity index 2000, SLEDAI-2K) were also established.

Results. Anti-PC were detected in $54.5 \%$ of patients and APCR in 59\%. Anti-PC positivity was associated with APCR to both rhAPC $(p<0.0001)$ and Protac ${ }^{\circ}(p=0.0001)$. High-avidity anti-PC, detected in $26.3 \%$ of SLE patients, were associated with APCR in patients with thrombosis only $(p<0.05)$, and with the development of thrombosis over time (range: $0-52$ years; $p=0.014)$. Highavidity anti-PC levels correlated with SLEDAI-2K ( $p=0.033)$ and total BILAG $(p=0.019)$; SLEDAI-2K correlated inversely with APCR to Protac $(p=0.004)$.

Conclusion. Anti-PC occur in patients with SLE, independently of aPL profile, and are associated with APCR. High-avidity anti-PC are associated with thrombosis and with active disease and might prove a novel marker to monitor the risk of thrombosis and disease progression in SLE.

KEYWORDS: systemic lupus erythematosus, anti-protein $\mathrm{C}$ antibodies, thrombosis, antiphospholipid antibodies, activated protein $\mathrm{C}$ resistance

\section{KEY MESSAGES}

- Anti-protein C antibodies (anti-PC) are present in $>50 \%$ of patients with systemic lupus erythematosus (SLE) 
- High-avidity anti-PC are associated with activated protein $\mathrm{C}$ resistance and thrombosis, independently of antiphospholipid antibodies

- High-avidity anti-PC are associated with disease activity in SLE, independently of aPL

WORD COUNT: 3596 


\section{INTRODUCTION}

Systemic lupus erythematosus (SLE) is a multi-organ autoimmune disease associated with a higher thromboembolic risk compared to the general population and to other inflammatory disorders $(1,2)$, which causes a significant burden of disability (3) and accounts for up to $26 \%$ of overall patient mortality (4). Patients with SLE have an up to 20 -fold increased risk of venous thromboembolism (VTE) compared to healthy subjects (5). They also develop frequent arterial thrombotic events, especially in the early course of the disease $(6,7)$. Antiphospholipid antibodies (aPL; lupus anticoagulant (LA), anti- $\beta 2$ glycoprotein I (aß2GPI) and/or anticardiolipin (aCL) antibodies) constitute major drivers of hypercoagulability and thromboembolism $(8,9)$ and are detectable in $30-40 \%$ of patients with SLE (10).

Antiphospholipid syndrome (APS) develops in 7-22\% of SLE cases $(11,12)$. Antiphospholipid antibodies might also synergise with other ischaemic determinants (4), such as accelerated atherosclerosis and abnormal interactions among platelets, leukocytes and endothelial cells (13-15). Conventional cardiovascular risk factors fail to account fully for the thrombotic diathesis in SLE (16). Disease-specific factors might also account for a high prevalence of thromboembolic events even in the absence of aPL (17). Dysfunctional haemostasis is increasingly appreciated as a potential driver of SLE-associated cardiovascular morbidity (18-22) and might also influence inflammation due to the extensive interactions between the coagulation and inflammatory cascades (23).

The anticoagulant protein $\mathrm{C}$ pathway plays a central role in the regulation of blood clotting and inflammation (24). Specifically, activated protein C (APC) effectively prevents excessive thrombin formation through its regulatory activity over activated factor $(F) V$ and FVIII. In addition, it exerts a key cytoprotective effect on the endothelium and inhibits the generation of neutrophil extracellular traps (NETs), a pathogenic hallmark of SLE (25). We therefore hypothesised that the protein $\mathrm{C}$ pathway could be a contributing factor in the coexistent hypercoagulable and inflammatory state observed in SLE. Previous evidence suggested that aPL could interfere with protein C activation and/or access to substrates (26-30). Acquired resistance to the anticoagulant actions of APC (acquired APC resistance, APCR), independent of heritable thrombophilic factors such as factor 
$\mathrm{V}$ Leiden, has been proposed to be contributory to thrombotic risk. When assessed using the thrombin generation (TG) system, which provides a global assessment of coagulation function, APCR is associated with thrombosis in aPL-positive patients (31). Patients with APS and previous VTE exhibit increased APCR, which is associated with a high prevalence of high avidity lgG antibodies against protein $\mathrm{C}$ (anti-PC) and a more severe thrombotic phenotype (recurrent VTE and/or arterial thrombosis despite therapeutic anticoagulation) $(32,33)$. Little is known about the presence and role of anti-PC and APCR in patients with SLE.

The aim of this cross-sectional study was to determine the prevalence and avidity of anti-PC, the prevalence of APCR, and examine associations with aPL status, disease activity, and thromboembolic (venous and arterial) and inflammatory manifestations in a well characterised cohort of patients with SLE.

\section{METHODS}

\section{Patients and samples}

One hundred patients with SLE, classified according to the revised American College of Rheumatology (ACR) 1997 criteria (34) were recruited from the Lupus and Haematology Clinics at University College London Hospital (UCLH), London, UK. Stored sera from an additional 56 patients with SLE were also studied to reach a sample size exceeding $80 \%$ statistical power for the detection of anti-PC, based on previous strudies (32). Exclusion criteria were heritable thrombophilia, history of malignancy or myeloproliferative neoplasms and treatment with oestrogen preparations. Patients with APS fulfilled the revised international consensus criteria for APS (9) and had been receiving anticoagulation for at least six months since the thromboembolic event prior to being recruited. Disease activity was assessed by the British Isles Lupus Assessment Group (BILAG)-2004 index (35) and the SLE disease activity index-2000 (SLEDAI-2K) (36). BILAG categories were converted into numbers according to the 2010 coding scheme (37). One hundred healthy controls were also recruited from staff members (none had SLE or aPL). Written informed consent was obtained from all subjects in accordance with the Declaration of Helsinki. Ethical approval was granted by the Research Ethics Committee NREC (reference: 13/NI/0049) and from the Research and 
Development office at UCLH (reference: 13/0030). Clinical data were retrospectively collected from medical charts and included demographics, general disease characteristics over time, persistent complement consumption, anti-DNA antibody levels, damage accrual (using the SLE International Collaborating Clinics/ACR damage index, SDI) (38), history of thrombotic events and medication. Antiphospholipid antibodies had been routinely assessed in the hospital laboratory with diagnostic procedures and assessment of aPL profile and status at time of sampling performed in accordance with international consensus criteria and national guidelines $(9,39,40)$ (see Supplementary Methods). A positive aPL profile was defined as the presence of at least one aPL confirmed by repeat assessment at least 12 weeks apart with antibody titres exceeding the $99 \%$ percentile of the laboratory reference range in patients' history (9). In addition, aPL levels at last measurement per routine clinical practice were recorded when available or tested as per the above criteria to determine patients' status at time of sampling.

Venous blood was collected using a 21-gauge butterfly needle, with minimal venous stasis, into $5 \mathrm{ml}$ Vacutainer® tubes (Becton Dickinson, Plymouth, UK) containing 0.105M citrate. Platelet poor plasma was prepared within two hours of collection by double centrifugation at ambient temperature ( $2000 \mathrm{~g}$ for 15 minutes) and stored in aliquots at $-80^{\circ} \mathrm{C}$. Immediately prior to analysis the samples were thawed in a water bath at $37^{\circ} \mathrm{C}$.

Patients were stratified into four groups, according to aPL profile and thrombosis: aPLpositive and thrombosis-positive (Group 1), aPL-positive with no history of thrombosis (Group 2), aPL-negative with history of thrombosis (Group 3) and patients with neither aPL nor thrombosis (Group 4).

\section{Anti-protein C antibody detection and avidity}

Anti-PC presence and avidity were assessed with an in-house ELISA as previously described (32, 33)(see also Supplementary Methods). Optical densities were standardised between plates using standardised temperature and development time and by comparing positive and negative controls. Samples were considered positive for anti-PC if values were $>99^{\text {th }}$ centile of the normal controls 
(36U/ml; (32, 33)). Anti-PC was evaluated in 156 patients (100 patients recruited and 56 patients stored sera).

Avidity was assessed as described in (32) and (41) by repeating the above procedures for samples positive for anti-PC with sample buffer containing $0.1,0.15,0.25,0.5,1.0,2.0,4.0$ or $6.0 \mathrm{M}$ $\mathrm{NaCl}$. Avidity was expressed as the percentage of maximum binding at $0.1 \mathrm{M} \mathrm{NaCl}$ which was arbitrarily considered as $100 \%$. High avidity was defined as $>60 \%$ of the initial binding and low avidity as $<25 \%$ at $1 \mathrm{M} \mathrm{NaCl}$.

\section{Acquired resistance to APC by thrombin generation}

Thrombin generation was assessed with the calibrated automated thrombinoscope (Diagnostica Stago, Maastricht, The Netherlands) (32), using PPP-Reagent (Diagnostica Stago, 5pM tissue factor and $4 \mu \mathrm{M}$ phospholipids; see also Supplementary Methods). Samples from patients taking oral anticoagulants were tested in equal volume mixtures with pooled normal plasma to correct for coagulation factor deficiency. Resistance to exogenous APC was determined using recombinant (rh) APC, and to activation of endogenous protein $\mathrm{C}$ using Protac $\AA$, an enzyme that converts protein $\mathrm{C}$ into APC (Pentapharm AG, Basel, Switzerland). APCR was expressed as percentage (\%) inhibition of endogenous thrombin potential (ETP), where ETP is the amount of thrombin formed in vitro in a clotting reaction and reflects the in vivo capacity of an individual to generate thrombin. Cut-off levels for APCR were set at $<56 \%$ for rhAPC and $<63 \%$ for Protac $\AA$, that was the $99^{\text {th }}$ centile in 100 normal controls.

\section{Statistical analysis}

Continuous variables were tested for normality using the Shapiro-Wilk's test. Student's t-test or ANOVA with Bonferroni's correction for multiple comparisons were employed to compare single, normally distributed continuous variables among two or multiple groups respectively. MannWhitney's or Kruskal-Wallis' tests were employed for non-normally distributed variables. Univariate association analysis among categorical variables was performed by chi-square test with Fisher's exact correction as appropriate. Binary regression analysis was performed to assess the relative 
contribution of multiple variables to binary outcomes. Cox's regression analysis was employed to retrospectively estimate the potential association of groups to time-dependent outcomes such as thrombosis, death or damage accrual. A probability value, $\mathrm{p}<0.05$ was considered statistically significant. Statistical analysis was performed by StataCorp STATA®, version 15.1 and Microsoft Excel ${ }^{\circledR}$ 2019. Data are expressed as median (interquartile range) unless otherwise specified.

\section{RESULTS}

The demographics and general clinical features of the 156 patients with SLE are reported in Table 1. The ethnicity of the patients we have studied reflects that of the UCL cohort as a whole, with a predominance of Caucasians and significant Black and Asian representation (42). Data about their thrombotic history, anticoagulant and anti-platelet treatment profile are provided in Supplementary Table 1 and 2. There were no differences between the patient groups in terms of demographics, prevalence of SLE clinical features and disease activity at the time of sample collection. However, patients in Group 3 had a lower prevalence of raised anti-DNA antibodies $\left(X^{2}=11.829 ; p=0.009\right)$ and pooled patients with a history of thrombosis were slightly older (mean $\pm S D=50.93 \pm 13.20$ years) than patients without thrombosis (mean $\pm S D=46.23 \pm 12.31$ years; $p=0.039$ ).

\section{Anti-PC in patients with SLE}

Anti-PC were found in $85 / 156$ patients (54.5\%), with no difference in frequency or antibody levels between groups (Figure 1A), even after stratifying for aPL and thrombotic profile (Figure 1B) or for treatment history. However, higher levels of anti-PC were found in patients with aCL IgM [46.6 (36.5$69.5)$ vs 35.522 .960 .4$) \mathrm{U} / \mathrm{ml} ; \mathrm{p}=0.025)$, aBeta2GPI IgM [45.4 (35.3-73.0) vs 35.5 (22.9-58.6) $\mathrm{U} / \mathrm{ml} ; \mathrm{p}=0.020]$ and LA [44.5 (30.4-68.7) vs 35.9 (22.8-54.5) $\mathrm{U} / \mathrm{ml} ; \mathrm{p}=0.032]$ at time of sampling. AntiPC levels also correlated with aCL IgG levels at time of sampling (rho=0.286; $p=0.006$ ). An overall positive aPL status (i.e. any positive among aCL $\lg G$ or $\lg M$, aBeta2GPI lgG or $\lg M$ or $L A C$ ) or a triple positive status at time of sampling did not associate with higher anti-PC levels.

High-avidity anti-PC were detected in $26.3 \%$ of all patients with SLE and in $48.2 \%(41 / 85)$ of the anti-PC positive patients. The frequency of high-avidity anti-PC was independent of anti-PC 
levels, diagnosis group and aPL profile (Figure 1C) or status at time of sampling and treatment history. Anti-cardiolipin and aB2GPI IgG and IgM levels were not different between patients with high- vs low-avidity anti-PC.

Retrospectively, patients with high-avidity anti-PC were more likely to have developed thrombosis over time (Log-rank=6.55; hazard ratio=2.57,95\% $\mathrm{Cl}=1.21-5.45 ; \mathrm{p}=0.014$; Figure 2), independent of aPL profile. Anti-PC and high-avidity anti-PC prevalence did not differ between patients with arterial and venous thromboembolism.

\section{Thrombin generation and acquired activated protein $\mathrm{C}$ resistance}

Platelet poor plasma from 100 patients ( $n=24, n=25, n=14$ and $n=37$ in groups $1-4$ respectively) was tested for APCR to rhAPC and to Protac $\AA$ using TG. Fifty-nine patients had APCR (to either rhAPC or Protac $\AA$ ) with $29 \%$ exhibiting dual resistance (resistance to both rhAPC and Protac $\AA$ ). Prevalence of APCR was homogeneous among the four groups for both rhAPC and Protac (Figure 3A). Similar results were obtained when patients were stratified by aPL profile or status and thrombosis, although patients without thrombosis had a higher prevalence of dual resistance $\left(x^{2}=5.2 ; p=0.025\right)$. Dual APCR was slightly more prevalent in patients with positive aCL $\operatorname{lgM}\left(x^{2}=4.801 ; p=0.049\right)$. No differences were found when patients were stratified for treatment history.

When TG data were compared with the results of anti-PC measurement, a triad of association among anti-PC, APCR by rhAPC and APCR by Protac® emerged. Anti-PC levels were inversely correlated with the \%inhibition of ETP obtained with either rhAPC (rho=-0.416; $<<0.0001$ ) or Protac $\AA$ (rho=-0.375; $\mathrm{p}=0.0001$ ). Patients positive for anti-PC had lower \%inhibition of ETP by either rhAPC $[$ mean $\pm S D=58.08 \pm 25.70$ vs $88.39 \pm 30.56 ; p<0.0001]$ or Protac $\AA[51.11(30.14-69.12)$ vs 74.33 (48.99-104.05); $p=0.0011]$ compared to anti-PC negative patients. Positive anti-PC were also more frequent among patients with overt APCR (i.e. ETP inhibition below the threshold for APCR; $x^{2}=16.4$; $p<0.001$ by rhAPC; $x^{2}=8.0 ; p=0.006$ by Protac $\Theta$ ) compared to anti-PC-negative patients (Figure 3B). Patients with APCR consistently had higher anti-PC levels [38.21 (28.85-49.52) vs 27.05 (21.1035.67) $\mathrm{U} / \mathrm{ml} ; \mathrm{p}=0.002$ ]. This association triad was reproduced after stratifying for aPL profile (Table 2) and status at time of sampling (Supplementary Table 3) in both aPL+ and aPL- patients. By 
contrast, categorising patients according to their thrombotic history revealed a dichotomy between thrombosis-positive patients, for whom positivity for anti-PC was associated with APCR to Protac but not rhAPC, and thrombosis-negative patients showing the opposite phenotype (Table 2).

When compared to low-avidity anti-PC, high-avidity anti-PC were associated with APCR to rhAPC and to Protac $\AA$ in thrombosis-positive patients only $\left(7 / 13\right.$ vs $0 / 6, X^{2}=5.1, p=0.044$ and $11 / 13$ vs $2 / 6, \quad x^{2}=5.0, p=0.046$ respectively). These associations were more generally evident, independently of aPL profile or status and thrombosis history when low-avidity anti-PC patients were pooled with negative anti-PC patients, except for thrombosis-negative patients, who did not show any association between anti-PC and APCR by Protac® (Table 2 and Supplementary Table 3). Further stratification by aPL specificities (aCL, aBeta2GPI, LAC) and isotypes ( $\lg$, $\lg M)$ at time of sampling, revealed a relatively stronger association among anti-PC, especially with high-avidity, APCR to rhAPC and to Protac in patients without aPL (Supplementary Table 4). No differences were found when comparing patients with arterial thrombotic events to patients with venous thromboembolism.

\section{Associations between anti-PC and APCR with non-thrombotic SLE phenotypes}

Considering the whole patient cohort, no significant association was detected among anti-PC levels, \%inhibition of ETP by Protac $®$ or rhAPC and disease activity scores or SLE manifestations including damage accrual (SDI score). There was, however, an inverse correlation between APCR to rhAPC and history of lupus rash (20/36 patients with APCR vs 50/64 with normal response to rhAPC; $\left.x^{2}=5.589 ; p=0.024\right)$.

In patients with high-avidity anti-PC, SLEDAI-2K scores correlated inversely with \%inhibition of ETP by $\operatorname{Protac} \AA(r h o=-0.549 ; p=0.004)$ and with anti-PC levels ( $r h o=0.334 ; p=0.033)$. In the same patients, anti-PC levels also correlated with the total BILAG score (rho=0.365; $p=0.019)$. Patients with high-avidity anti-PC showed an increased frequency of photosensitive rash in their disease history (25/41) compared to patients with low-avidity anti-PC $\left(13 / 44, x^{2}=8.481 ; p=0.005\right)$. 


\section{Multivariate analysis for factors associating with high-avidity anti-PC}

Binary logistic regression analysis revealed that high-avidity anti-PC were significantly associated with impaired \%inhibition of ETP by rhAPC and Protac®, irrespectively of anti-PC levels and aPL status at time of sampling, but not of thrombotic history. An association with a history of photosensitive rash was also confirmed (Table 3). Similar results were obtained by substituting aPL status with aPL profile in the model (data not shown).

\section{DISCUSSION}

In this cross-sectional study of well characterised patients with SLE we made the novel observation that anti-PC were present in 55\% (85/156) of overall patients, with approximately half of these exhibiting high-avidity anti-PC, independent of aPL profile or status at time of sampling. We also found that 59 of 100 patients with SLE tested had APCR, with the novel observation that 29/100 exhibited resistance to both exogenous APC and to activation of endogenous protein C. Anti-PC were associated with APCR to both exogenous APC and to activation of endogenous protein C. More importantly, we established that high avidity anti-PC were associated with APCR only in patients with thrombosis suggesting a possible relationship between these two parameters and the development of thrombosis. We showed for the first time that high avidity anti-PC were consistently associated with the occurrence of thrombosis over time, suggesting that high avidity anti-PC might have a functional impact on haemostasis in SLE by interfering with the protein C pathway. Patients with high-avidity anti-PC also had an increased frequency of photosensitive rash in their disease history. Interestingly, in these patients, we also found a significant correlation between anti-PC levels and SLEDAI-2K scores and between SLEDAI-2K scores and \%inhibition of ETP by Protac®, indicating that dysfunction in the protein $\mathrm{C}$ pathway might either contribute to the inflammatory events characterising SLE pathogenesis and/or be affected by them at the same time.

APCR is a major risk factor for thrombosis (43), thus constituting a biologically plausible pathogenic mechanism at the crossroads between inflammation and haemostasis $(23,44)$. Many previous studies have confirmed that APCR is frequently present in SLE (23, 26, 44-47). Using a 
dual approach, we assessed for the first time the integrity of endogenous protein $\mathrm{C}$ activation and of the downstream effects of APC, and we identified that both these aspects are dysfunctional in SLE. Several studies assessed APCR with conflicting results. Despite a general concordance in the association between APCR and thrombosis, some reports $(44,45,48,49)$ but not all $(46)$ observed a prolongation in activated partial thromboplastin time (APTT) after adding APC, suggesting a link between APCR and aPL. Notably, the use of aPTT alone to assess APCR is insufficient, especially as it cannot be used to investigate defects in the activation of endogenous protein $\mathrm{C}$, since it does not mirror the prevailing mechanisms enhancing TG in vivo. Zuily et al. measured APCR by TG and prospectively followed up 30 patients with SLE (16 aPL+) and 62 patients with aPL (38/62 with a history of thrombosis) for a median time of 35 months, recording 18 new thrombotic events. Associations between thrombosis and APCR were identified, but only in the presence of aPL. However, little can be inferred regarding patients with SLE, as no SLE patient had a previous history of, or developed a thrombotic event, during that study (47).

In order to minimise potential biases due to underrepresentation of single SLE subgroups or lack of homogeneity in disease duration leading to underestimation of thrombotic risk and to obtain a more accurate, global measure of TG dynamics in SLE patients, we a) studied a relatively large number of patients with SLE with a balanced representation of patients with aPL and thrombotic events; b) normalised thrombotic risk for time; and c) measured APCR through TG. In our cohort, we did not identify any clear association between aPL and APCR, which suggests that other acquired factors in addition to aPL might also account for APCR and an increased thrombotic risk in patients with SLE (33). More importantly, we made the novel observation that patients with SLE harbour antiPC along their autoimmune serological profile and demonstrated that anti-PC correlate with APCR, which might imply a direct functional role for them in causing APCR in these patients. Furthermore, in line with previous evidence in APS $(32,33)$, we observed that high-avidity anti-PC were selectively associated with a thrombotic phenotype in patients with SLE, suggesting that these antibodies may contribute to the development of thrombotic complications in SLE. Although anti-PC levels were globally higher in patients with positive aCL $\lg M$, antiBeta2GPI IgM or LAC at time of sampling and correlated with aCL IgG levels, no consistent association with aPL profile or status was found for 
high-avidity anti-PC, suggesting that only the latter might have a pathogenic role. Nonetheless the differential association of anti-PC, rhAPC and Protac when stratified for positive of negative patients for each single antibody isotype suggests that at least in some subsets of patients multiple prothrombotic factors might accrue at the same time.

An additional novel finding was that high-avidity anti-PC were also associated with nonthrombotic SLE manifestations and with higher disease activity scores, possibly suggesting an additional link between the presence of these antibodies and the course of inflammation in SLE. Unique inflammatory events, possibly linking impaired APC activity with endothelial activation and/or aberrant platelet/leukocyte interactions in SLE independently of aPL, might also account for the lack of differentiation between patients with arterial and venous thrombosis in our study, in contrast to the venous-dominant phenotype observed in APS (32). Consistently similar rates of venous and arterial events were found in the history of patients in Group 3 (thrombosis-positive, aPL-negative), who represent a less characterised, but clinically significant subset of patients with SLE, corroborating previous evidence suggesting that patients with SLE are susceptible to both arterial and venous thrombotic events independent of aPL $(10,17,50,51)$.

Limitations of this study include the retrospective nature of the data regarding time to thrombosis. This analysis also started from the assumption of positive anti-PC having invariant status in patients with SLE, which is supported by the homogenous distribution of anti-PC among age and disease duration groups and by the notion of epitope spreading early in the course of autoimmune diseases including SLE $(52,53)$. Larger prospective studies with serial measurements of anti-PC antibodies over time are needed to corroborate the potential role of these serological abnormalities as additional markers of disease activity. Validation in an independent cohort and assessment of the prevalence of anti-PC in other unrelated conditions will also add to the evidence provided by this work regarding the general role of these antibodies in inflammation and haemostasis. The potential role of other non-criteria aPL (such as anti-domain I B2GP1 or anti-phosphatidylserine/prothrombin antibodies) in this complex setting (especially in patients negative for aPL with thrombotic manifestations) deserves further investigation. Similarly, the possible association of anti-PC with non-thrombotic manifestations in APS and SLE such as cardiac valve disease or thrombocytopenia 
constitutes a fascinating topic for future studies. In conclusion, we found that anti-PC can be detected in more than half of patients with SLE, and show high avidity in about $50 \%$ of cases independently of aPL status. High-avidity anti-PC are associated with APCR in patients with thrombotic events, and also with disease activity, suggesting that these antibodies are not just 'silent bystanders' in the immuno-haemostatic continuum and along with APCR could become novel markers to identify patients at increased risk of thrombosis and, possibly, of active disease, independent of aPL. Integrating these two parameters into current clinical-pathological paradigms could identify novel opportunities for personalised early therapeutic intervention and pave the way to generate more accurate diagnostic and therapeutic tools for patient management.

ACKNOWLEDGMENTS: the authors want to thank all patients involved in this research for their collaboration. We are also grateful to Miss Eve McLoughlin, for collecting blood samples and to Dr. Beatriz Tejera-Segura, Dr. Rekha Lopez and Prof. Anisur Rahman for providing the basis for the clinical database employed in this study.

AUTHORSHIP STATEMENT: ME designed the study. HC, DAI, IM and GAR contributed to the design of the study. ME, GAR performed the majority of experiments.SN and CP performed part of the aPL experiments. GAR, SN, RM and TP collected clinical data. GAR and ME analysed the results and drafted the manuscript. All authors contributed in critical revision of the manuscript. All authors approved the final version of the article and agree to be accountable for all aspects of the work in ensuring that questions related to the accuracy or integrity of any part of the work will appropriately be investigated and resolved.

FUNDING STATEMENT: This study was supported by the Rheumatology Discretionary Fund UCL Charity and the Haematology UCLH Charity Fund.

CONFLICT OF INTEREST STATEMENT: Dr. Mackie reports grants from Rheumatology Discretionary Fund, UCL Charity and grants from Haematology UCLH Charity Fund, during the 
conduct of the study. Prof. Cohen reports Institutional research support, Travel support Honoraria for lectures paid to Institution's Charity by Bayer and Consultancy fees paid to Institution's Charity by UCB, during the conduct of the study.

\section{DATA AVAILABILITY STATEMENT}

The data underlying this article will be shared on reasonable request to the corresponding author. 


\section{REFERENCES}

1. Haque S, Gordon C, Isenberg D, Rahman A, Lanyon P, Bell A, et al. Risk factors for clinical coronary heart disease in systemic lupus erythematosus: the lupus and atherosclerosis evaluation of risk (LASER) study. J Rheumatol. 2010;37(2):322-9.

2. Pego-Reigosa JM, Lu TY, Fontanillo MF, del Campo-Perez V, Rahman A, Isenberg DA. Long-term improvement of lipid profile in patients with refractory systemic lupus erythematosus treated with B-cell depletion therapy: a retrospective observational study. Rheumatology (Oxford). 2010;49(4):691-6.

3. Yelin E, Tonner C, Trupin L, Gansky SA, Julian L, Katz P, et al. Longitudinal study of the impact of incident organ manifestations and increased disease activity on work loss among persons with systemic lupus erythematosus. Arthritis Care Res (Hoboken). 2012;64(2):169-75.

4. Cervera R, Khamashta MA, Font J, Sebastiani GD, Gil A, Lavilla P, et al. Morbidity and mortality in systemic lupus erythematosus during a 10-year period: a comparison of early and late manifestations in a cohort of 1,000 patients. Medicine (Baltimore). 2003;82(5):299-308.

5. Avina-Zubieta JA, Vostretsova K, De Vera MA, Sayre EC, Choi HK. The risk of pulmonary embolism and deep venous thrombosis in systemic lupus erythematosus: A general population-based study. Semin Arthritis Rheum. 2015;45(2):195-201.

6. Sarabi ZS, Chang E, Bobba R, Ibanez D, Gladman D, Urowitz M, et al. Incidence rates of arterial and venous thrombosis after diagnosis of systemic lupus erythematosus. Arthritis Rheum. 2005;53(4):609-12.

7. Chambers SA, Allen E, Rahman A, Isenberg D. Damage and mortality in a group of British patients with systemic lupus erythematosus followed up for over 10 years. Rheumatology (Oxford). 2009;48(6):6735.

8. Cervera R, Serrano R, Pons-Estel GJ, Ceberio-Hualde L, Shoenfeld Y, de Ramon E, et al. Morbidity and mortality in the antiphospholipid syndrome during a 10-year period: a multicentre prospective study of 1000 patients. Ann Rheum Dis. 2015;74(6):1011-8.

9. Miyakis S, Lockshin MD, Atsumi T, Branch DW, Brey RL, Cervera R, et al. International consensus statement on an update of the classification criteria for definite antiphospholipid syndrome (APS). J Thromb Haemost. 2006;4(2):295-306.

10. Mok CC, Tang SS, To CH, Petri M. Incidence and risk factors of thromboembolism in systemic lupus erythematosus: a comparison of three ethnic groups. Arthritis Rheum. 2005;52(9):2774-82.

11. Ruiz-Irastorza G, Egurbide MV, Ugalde J, Aguirre C. High impact of antiphospholipid syndrome on irreversible organ damage and survival of patients with systemic lupus erythematosus. Arch Intern Med. 2004;164(1):77-82.

12. Tello BDCG, Jones A, Raine C, Isenberg D, editors. Systemic Lupus Erythematosus: Detailed Anatomy of a Cohort (follow-up for more than 35 years). Arthritis \& rheumatology; 2016: WILEY 111 RIVER ST, HOBOKEN 07030-5774, NJ USA.

13. Joseph JE, Harrison P, Mackie IJ, Isenberg DA, Machin SJ. Increased circulating platelet-leucocyte complexes and platelet activation in patients with antiphospholipid syndrome, systemic lupus erythematosus and rheumatoid arthritis. Br J Haematol. 2001;115(2):451-9.

14. Ramirez GA, Efthymiou M, Isenberg DA, Cohen H. Under crossfire: thromboembolic risk in systemic lupus erythematosus. Rheumatology (Oxford). 2019;58(6):940-52.

15. Ramirez GA, Rovere-Querini $P$, Sabbadini MG, Manfredi AA. Parietal and intravascular innate mechanisms of vascular inflammation. Arthritis research \& therapy. 2015;17(1):16.

16. Bessant R, Duncan R, Ambler G, Swanton J, Isenberg DA, Gordon C, et al. Prevalence of conventional and lupus-specific risk factors for cardiovascular disease in patients with systemic lupus erythematosus: $A$ case-control study. Arthritis Rheum. 2006;55(6):892-9.

17. Tektonidou MG, Laskari K, Panagiotakos DB, Moutsopoulos HM. Risk factors for thrombosis and primary thrombosis prevention in patients with systemic lupus erythematosus with or without antiphospholipid antibodies. Arthritis Rheum. 2009;61(1):29-36.

18. Palatinus A, Adams M. Thrombosis in systemic lupus erythematosus. Semin Thromb Hemost. 2009;35(7):621-9. 
19. Mehta BM, Kiani AN, Chen C, Jani J, Kickler TS, Petri M. Endogenous thrombin potential in the assessment of hypercoagulability in systemic lupus erythematosus. Am J Hematol. 2010;85(1):83-5.

20. Kern A, Barabas E, Balog A, Burcsar S, Kiszelak M, Vasarhelyi B. Characterization of the thrombin generation profile in systemic lupus erythematosus. Physiol Int. 2017;104(1):35-41.

21. Pereira J, Alfaro G, Goycoolea M, Quiroga T, Ocqueteau M, Massardo L, et al. Circulating plateletderived microparticles in systemic lupus erythematosus. Association with increased thrombin generation and procoagulant state. Thromb Haemost. 2006;95(1):94-9.

22. Liestol S, Sandset PM, Jacobsen EM, Mowinckel MC, Wisloff F. Decreased anticoagulant response to tissue factor pathway inhibitor type 1 in plasmas from patients with lupus anticoagulants. $\mathrm{Br} \mathrm{J}$ Haematol. 2007;136(1):131-7.

23. Meesters EW, Hansen H, Spronk HM, Hamulyak K, Rosing J, Rowshani AT, et al. The inflammation and coagulation cross-talk in patients with systemic lupus erythematosus. Blood Coagul Fibrinolysis. 2007;18(1):21-8.

24. Bouwens EA, Stavenuiter F, Mosnier LO. Mechanisms of anticoagulant and cytoprotective actions of the protein C pathway. J Thromb Haemost. 2013;11 Suppl 1:242-53.

25. Healy LD, Puy C, Fernandez JA, Mitrugno A, Keshari RS, Taku NA, et al. Activated protein C inhibits neutrophil extracellular trap formation in vitro and activation in vivo. J Biol Chem. 2017;292(21):8616-29.

26. Nojima J, Kuratsune $H$, Suehisa E, Iwatani $Y$, Kanakura $Y$. Acquired activated protein $C$ resistance associated with IgG antibodies against beta2-glycoprotein I and prothrombin as a strong risk factor for venous thromboembolism. Clin Chem. 2005;51(3):545-52.

27. Malia RG, Kitchen S, Greaves M, Preston FE. Inhibition of activated protein $C$ and its cofactor protein S by antiphospholipid antibodies. British journal of haematology. 1990;76(1):101-7.

28. Tsakiris DA, Settas L, Makris PE, Marbet GA. Lupus anticoagulant--antiphospholipid antibodies and thrombophilia. Relation to protein C--protein S--thrombomodulin. The Journal of rheumatology. 1990;17(6):785-9.

29. Gardiner C, Cohen H, Jenkins A, Machin SJ, Mackie IJ. Detection of acquired resistance to activated protein $\mathrm{C}$ associated with antiphospholipid antibodies using a novel clotting assay. Blood coagulation \& fibrinolysis : an international journal in haemostasis and thrombosis. 2006;17(6):477-83.

30. Marciniak E, Romond EH. Impaired catalytic function of activated protein C: a new in vitro manifestation of lupus anticoagulant. Blood. 1989;74(7):2426-32.

31. Liestol S, Sandset PM, Mowinckel MC, Wisloff F. Activated protein C resistance determined with a thrombin generation-based test is associated with thrombotic events in patients with lupus anticoagulants. J Thromb Haemost. 2007;5(11):2204-10.

32. Arachchillage DR, Efthymiou M, Mackie IJ, Lawrie AS, Machin SJ, Cohen H. Anti-protein C antibodies are associated with resistance to endogenous protein $C$ activation and a severe thrombotic phenotype in antiphospholipid syndrome. J Thromb Haemost. 2014;12(11):1801-9.

33. Efthymiou M, Arachchillage DRJ, Lane PJ, O'Keeffe AG, McDonnell T, Cohen $H$, et al. Antibodies against TFPI and protein $C$ are associated with a severe thrombotic phenotype in patients with and without antiphospholipid syndrome. Thromb Res. 2018;170:60-8.

34. Hochberg MC. Updating the American College of Rheumatology revised criteria for the classification of systemic lupus erythematosus. Arthritis and rheumatism. 1997;40(9):1725.

35. Isenberg DA, Rahman A, Allen E, Farewell V, Akil M, Bruce IN, et al. BILAG 2004. Development and initial validation of an updated version of the British Isles Lupus Assessment Group's disease activity index for patients with systemic lupus erythematosus. Rheumatology (Oxford). 2005;44(7):902-6.

36. Gladman DD, Ibanez D, Urowitz MB. Systemic lupus erythematosus disease activity index 2000. J Rheumatol. 2002;29(2):288-91.

37. Yee CS, Cresswell L, Farewell V, Rahman A, Teh LS, Griffiths B, et al. Numerical scoring for the BILAG2004 index. Rheumatology (Oxford). 2010;49(9):1665-9.

38. Gladman DD, Goldsmith $\mathrm{CH}$, Urowitz MB, Bacon P, Fortin P, Ginzler E, et al. The Systemic Lupus International Collaborating Clinics/American College of Rheumatology (SLICC/ACR) Damage Index for Systemic Lupus Erythematosus International Comparison. J Rheumatol. 2000;27(2):373-6. 
39. Pengo V, Tripodi A, Reber G, Rand JH, Ortel TL, Galli M, et al. Update of the guidelines for lupus anticoagulant detection. Subcommittee on Lupus Anticoagulant/Antiphospholipid Antibody of the Scientific and Standardisation Committee of the International Society on Thrombosis and Haemostasis. J Thromb Haemost. 2009;7(10):1737-40.

40. Keeling D, Mackie I, Moore GW, Greer IA, Greaves M, British Committee for Standards in H. Guidelines on the investigation and management of antiphospholipid syndrome. $\mathrm{Br} \mathrm{J}$ Haematol. 2012;157(1):47-58.

41. Cucnik S, Kveder T, Krizaj I, Rozman B, Bozic B. High avidity anti-beta 2-glycoprotein I antibodies in patients with antiphospholipid syndrome. Ann Rheum Dis. 2004;63(11):1478-82.

42. Medina-Quinones CV, Ramos-Merino L, Ruiz-Sada P, Isenberg D. Analysis of Complete Remission in Systemic Lupus Erythematosus Patients Over a 32-Year Period. Arthritis Care Res (Hoboken). 2016;68(7):9817.

43. Svensson PJ, Dahlback BJNEJoM. Resistance to activated protein $\mathrm{C}$ as a basis for venous thrombosis. 1994;330(8):517-22.

44. Munoz-Rodriguez FJ, Reverter JC, Font J, Tassies D, Espinosa G, Cervera R, et al. Clinical significance of acquired activated protein $C$ resistance in patients with systemic lupus erythematosus. Lupus. 2002;11(11):730-5.

45. Nojima J, Kuratsune H, Suehisa E, Kawasaki T, Machii T, Kitani T, et al. Acquired activated protein C resistance is associated with the co-existence of anti-prothrombin antibodies and lupus anticoagulant activity in patients with systemic lupus erythematosus. Br J Haematol. 2002;118(2):577-83.

46. Oh D, Kim SH, Kang MS, Kim NK, Chang NS, Na BW, et al. Acquired activated protein C resistance, high tissue factor expression, and hyper-homocysteinemia in systemic lupus erythematosus. Am J Hematol. 2003;72(2):103-8.

47. Zuily S, Regnault V, Guillemin F, Kaminsky P, Rat AC, Lecompte T, et al. Superficial vein thrombosis, thrombin generation and activated protein $C$ resistance as predictors of thromboembolic events in lupus and antiphospholipid patients. A prospective cohort study. Thromb Res. 2013;132(1):e1-7.

48. Martinuzzo M, Forastiero R, Adamczuk Y, Cerrato G, Carreras LJBc, haemostasis faiji, et al. Activated protein C resistance in patients with anti-beta 2 glycoprotein I antibodies. 1996;7(7):702-4.

49. Male C, Mitchell L, Julian J, Vegh P, Joshua P, Adams M, et al. Acquired activated protein C resistance is associated with lupus anticoagulants and thrombotic events in pediatric patients with systemic lupus erythematosus. 2001;97(4):844-9.

50. Chung WS, Lin CL, Chang SN, Lu CC, Kao CH. Systemic lupus erythematosus increases the risks of deep vein thrombosis and pulmonary embolism: a nationwide cohort study. J Thromb Haemost. 2014;12(4):4528.

51. Avina-Zubieta JA, To F, Vostretsova K, De Vera M, Sayre EC, Esdaile JM. Risk of Myocardial Infarction and Stroke in Newly Diagnosed Systemic Lupus Erythematosus: A General Population-Based Study. Arthritis Care Res (Hoboken). 2017;69(6):849-56.

52. Salem D, Subang R, Okazaki Y, Laplante P, Levine JS, Kuwana M, et al. beta2-Glycoprotein I-specific T cells are associated with epitope spread to lupus-related autoantibodies. J Biol Chem. 2015;290(9):5543-55.

53. Eriksson C, Kokkonen H, Johansson M, Hallmans G, Wadell G, Rantapaa-Dahlqvist S. Autoantibodies predate the onset of systemic lupus erythematosus in northern Sweden. Arthritis Res Ther. 2011;13(1):R30. 
Table 1: demographics and general clinical features

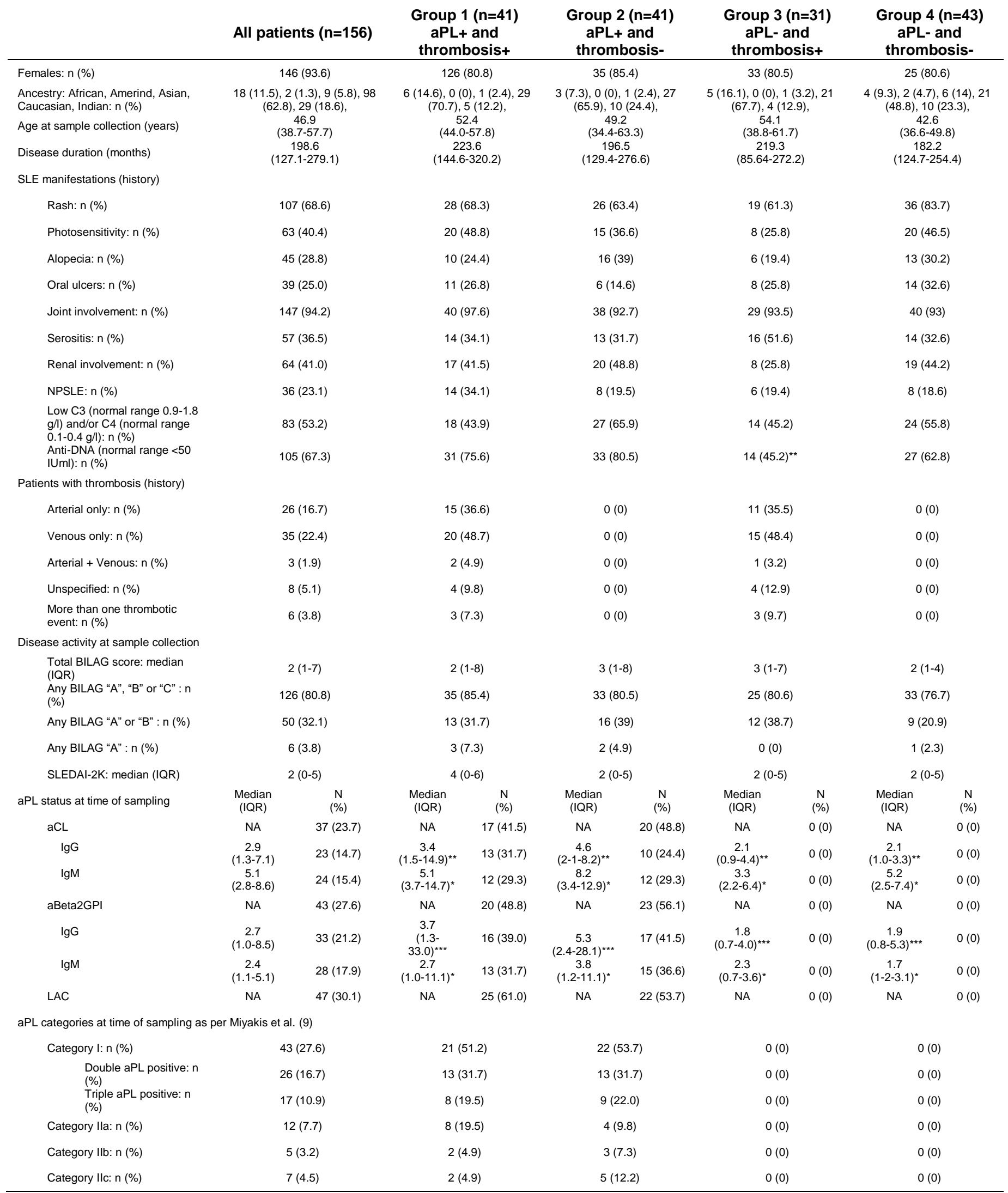

\section{Abbreviations}


aBeta2GPI: anti-beta2 glycoprotein I antibodies, aCL: anti-cardiolipin antibodies, anti-DNA: anti-DNA antibodies, aPL: antiphospholipid antibodies, BILAG: British Isles Lupus Assessment Group (index), LAC: lupus anticoagulant, NPSLE: neuropsychiatric lupus, SLEDAI: systemic lupus erythematosus disease activity index.

${ }^{* * *}: p<0.001,{ }^{* *}: p<0.01,{ }^{*}: p<0.05$ among all groups $\left.\right|^{\wedge}: p<0.05$ comparing Group 1 vs Group 2

Table 2: tripartite anti-PC-rhAPC-Protac associations by aPL profile and thrombosis

\begin{tabular}{|c|c|c|c|c|c|c|c|c|c|}
\hline & \multirow{2}{*}{$\begin{array}{c}\text { anti-PC } \\
\text { class }\end{array}$} & \multicolumn{2}{|c|}{$\begin{array}{l}\text { APCR by } \\
\text { rhAPC }\end{array}$} & \multicolumn{2}{|c|}{$\begin{array}{c}\text { APCR by } \\
\text { Protac }\end{array}$} & \multicolumn{2}{|c|}{ Any APCR } & \multicolumn{2}{|c|}{ Dual APCR } \\
\hline & & YES & NO & YES & NO & YES & NO & YES & NO \\
\hline \multirow{6}{*}{ aPL+ } & \multirow{2}{*}{ Pos vs Neg } & $15 / 20$ & $10 / 29$ & $18 / 27$ & $7 / 22$ & $21 / 32$ & $4 / 17$ & $12 / 15$ & $13 / 34$ \\
\hline & & \multicolumn{2}{|c|}{$p=0.009$} & \multicolumn{2}{|c|}{$p=0.022$} & \multicolumn{2}{|c|}{$p=0.007$} & \multicolumn{2}{|c|}{$p=0.012$} \\
\hline & \multirow{2}{*}{$H A$ vs $L A$} & $10 / 15$ & $5 / 10$ & $12 / 18$ & $3 / 7$ & $14 / 21$ & $1 / 3$ & $8 / 12$ & $7 / 13$ \\
\hline & & \multicolumn{2}{|c|}{$p=N S$} & \multicolumn{2}{|c|}{$p=N S$} & \multicolumn{2}{|c|}{$\mathrm{p}=\mathrm{NS}$} & \multicolumn{2}{|c|}{$p=N S$} \\
\hline & \multirow{2}{*}{$H A$ vs $L A+N e g$} & $10 / 20$ & $5 / 29$ & $12 / 27$ & $3 / 22$ & $14 / 32$ & $1 / 17$ & $8 / 15$ & $7 / 34$ \\
\hline & & \multicolumn{2}{|c|}{$\mathrm{p}=0.026$} & \multicolumn{2}{|c|}{$\mathrm{p}=0.029$} & \multicolumn{2}{|c|}{$p=0.008$} & \multicolumn{2}{|c|}{$p=0.041$} \\
\hline \multirow{6}{*}{ aPL- } & \multirow{2}{*}{ Pos vs Neg } & $12 / 16$ & $11 / 35$ & $14 / 25$ & $9 / 26$ & $16 / 27$ & $7 / 24$ & $10 / 14$ & $13 / 37$ \\
\hline & & \multicolumn{2}{|c|}{$p=0.006$} & \multicolumn{2}{|c|}{$\mathrm{p}=\mathrm{NS}$} & \multicolumn{2}{|c|}{$p=0.048$} & \multicolumn{2}{|c|}{$p=0.029$} \\
\hline & \multirow{2}{*}{$H A$ vs $L A$} & $7 / 12$ & $4 / 11$ & $9 / 14$ & $2 / 9$ & $9 / 16$ & $2 / 7$ & $7 / 10$ & $4 / 9$ \\
\hline & & \multicolumn{2}{|c|}{$p=N S$} & \multicolumn{2}{|c|}{$\mathrm{p}=\mathrm{NS}$} & \multicolumn{2}{|c|}{$\mathrm{p}=\mathrm{NS}$} & & \\
\hline & $H \Delta$ vc & $7 / 16$ & $4 / 35$ & $9 / 25$ & $2 / 26$ & $9 / 27$ & $2 / 24$ & $7 / 14$ & $4 / 37$ \\
\hline & 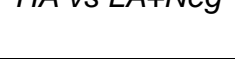 & & & & & & & & \\
\hline & & $7 / 10$ & $12 / 28$ & $13 / 17$ & $6 / 21$ & $15 / 21$ & $4 / 17$ & $5 / 6$ & $14 / 32$ \\
\hline & rus volveg & & & & & & & & \\
\hline Thrombosis & $H A$ vs $L A$ & $7 / 7$ & $6 / 12$ & $11 / 13$ & $2 / 6$ & $13 / 15$ & $0 / 4$ & $5 / 5$ & $8 / 14$ \\
\hline+ & 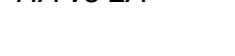 & & & & & & & & \\
\hline & HA va I A Ner & $7 / 10$ & $6 / 28$ & $11 / 17$ & $2 / 21$ & $13 / 21$ & $0 / 17$ & $5 / 6$ & $8 / 32$ \\
\hline & & & & & & & & & \\
\hline & Pos & $20 / 26$ & $9 / 36$ & $19 / 35$ & $10 / 27$ & $22 / 38$ & $7 / 24$ & $17 / 23$ & $12 / 39$ \\
\hline & rus vo iveg & & & & & $p=($ & & & \\
\hline Thrombncic & HA velA & $10 / 20$ & $3 / 9$ & $10 / 19$ & $3 / 10$ & $10 / 22$ & $3 / 7$ & $10 / 17$ & $3 / 12$ \\
\hline IIIOImousis- & ПН VS LA & & & & & & & & \\
\hline & $\mathrm{HA}$ ve I A $\mathrm{Neg}$ & $10 / 26$ & $3 / 36$ & $10 / 35$ & $3 / 27$ & $10 / 38$ & $3 / 24$ & $10 / 23$ & $3 / 39$ \\
\hline & 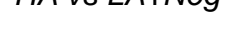 & & & & & & & & 02 \\
\hline
\end{tabular}

\section{Abbreviations}

anti-PC: anti-protein C antibodies, APCR: resistance to activated protein C, aPL: antiphospholipid antibodies, HA: high-avidity, LA: low avidity, Neg: negative, Pos: positive, rhAPC: recombinant human activated protein C. 
Table 3: binary logistic regression analysis for high-avidity anti-PC

\begin{tabular}{|c|c|c|c|c|}
\hline & $\begin{array}{c}\text { Beta } \\
\text { Coefficient }\end{array}$ & Standard error & $\begin{array}{c}95 \% \text { confidence } \\
\text { interval }\end{array}$ & $\mathbf{p}$ \\
\hline anti-PC levels (U/ml) & 0.029 & 0.028 & $-0.026-0.085$ & NS \\
\hline ETP inhibition by rhAPC & -0.049 & 0.021 & $-0.091--0.007$ & 0.021 \\
\hline ETP inhibition by Protac $\AA$ & -0.031 & 0.015 & $-0.060--0.002$ & 0.036 \\
\hline History of Thrombosis & 2.483 & 1.039 & $0.447-4.520$ & 0.017 \\
\hline Positive aPL status & -0.131 & 0.817 & $-1.732-1.470$ & NS \\
\hline History of photosensitivity & 2.402 & 1.096 & $0.253-4.551$ & 0.028 \\
\hline SLEDAI-2K score & -0.236 & 0.136 & $-0.502-0.031$ & NS \\
\hline
\end{tabular}

48 observations. Log likelihood $=-21.809$.

\section{Abbreviations}

anti-PC: anti-protein C antibodies, aPL: antiphospholipid antibodies, ETP: endogenous thrombin potential, rhAPC: recombinant human activated protein C, SLEDAl: systemic lupus erythematosus disease activity index. 

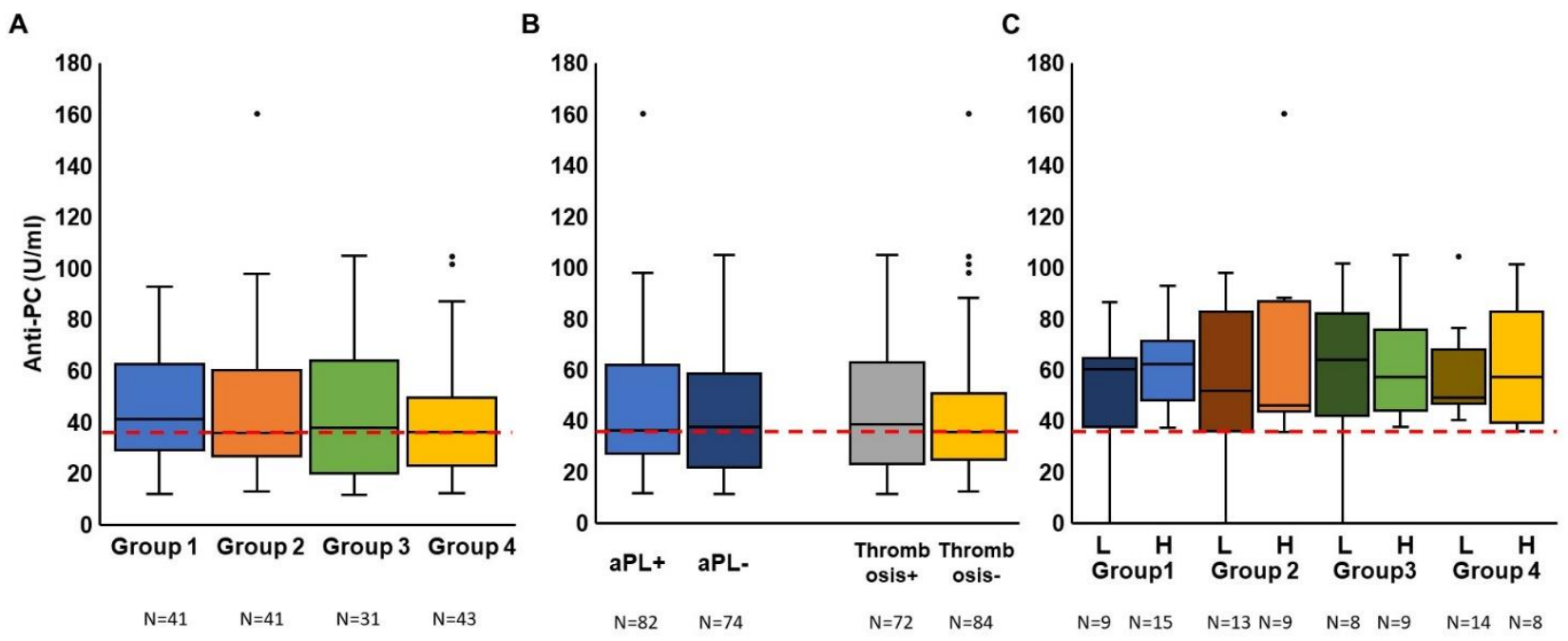

\section{LEGEND TO FIGURE 1: anti-PC in patients with SLE}

Box-plots showing levels of anti-PC in patients with SLE. The dots outside the boxes and whiskers represent outlier observations. Patients with SLE were stratified according to their aPL profile and thrombotic history. A: Group 1: aPL-positive and thrombosis-positive, Group 2: aPL-positive with no history of thrombosis, Group 3: aPL-negative with history of thrombosis, Group 4: patients with neither aPL nor thrombosis. B: Patients were pooled according to their aPL profile or thrombotic status. C. Patients positive for anti-PC were stratified by high $(\mathrm{H})$ - and low (L)-avidity anti-PC. Cutoff for positive anti-PC: $36 \mathrm{U} / \mathrm{ml}$ (red dashed line). Anti-PC levels did not differ among the different groups or when stratified according to aPL or thrombotic profile. 


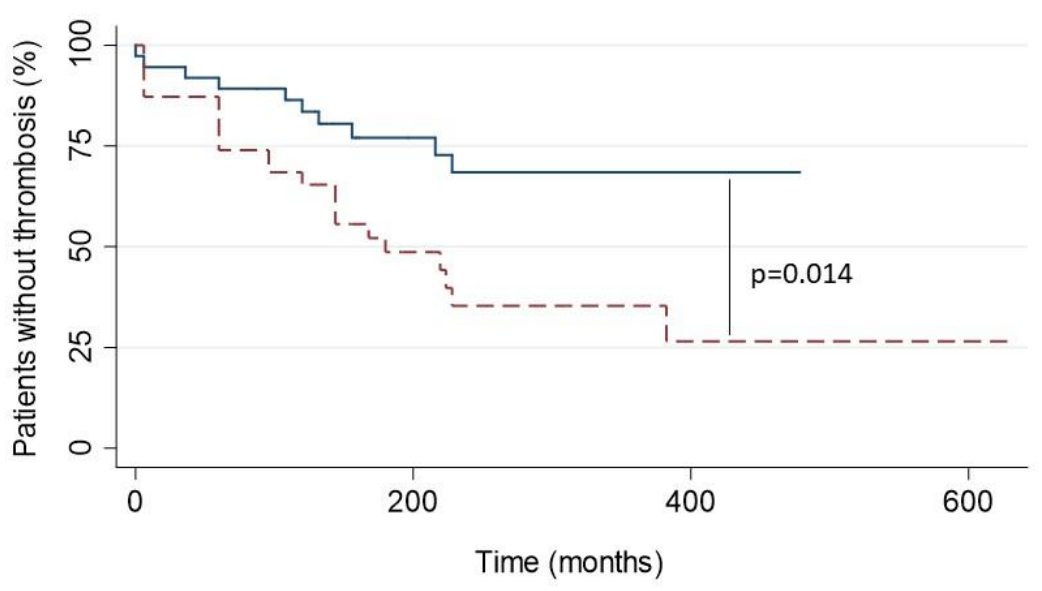

Number at risk

Low-avidity anti-PC 37

High-avidity anti-PC 39

18

12

2

3

Low-avidity anti-PC $\quad----\cdot$ High-avidity anti-PC

\section{LEGEND TO FIGURE 2: high-avidity anti-PC and thrombotic events}

Kaplan-Meier's survival curves showing the occurrence of thrombotic events in SLE patients with high- (red, dashed line) and low-avidity (blue, solid line) anti-PC over time. The table below the graph shows the number of patients with anti-PC (either high or low-avidity) having follow up data at each timepoint. Patients with high-avidity anti-PC had higher thrombosis rates compared to patients with low-avidity anti-PC. 
A

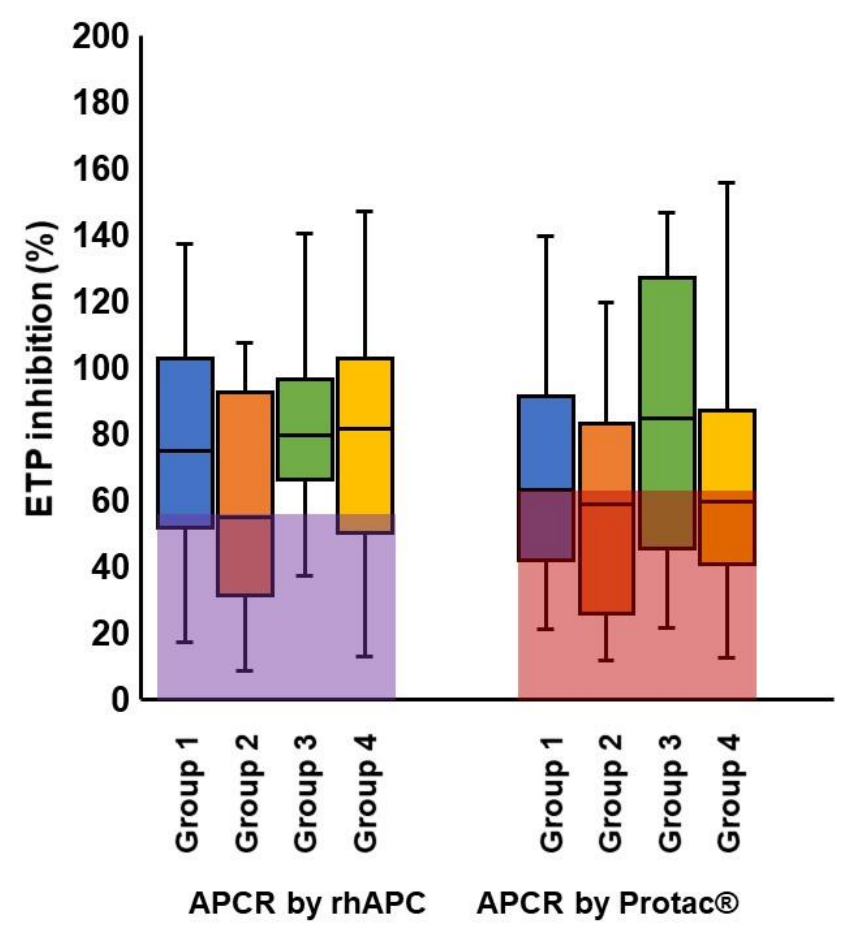

B

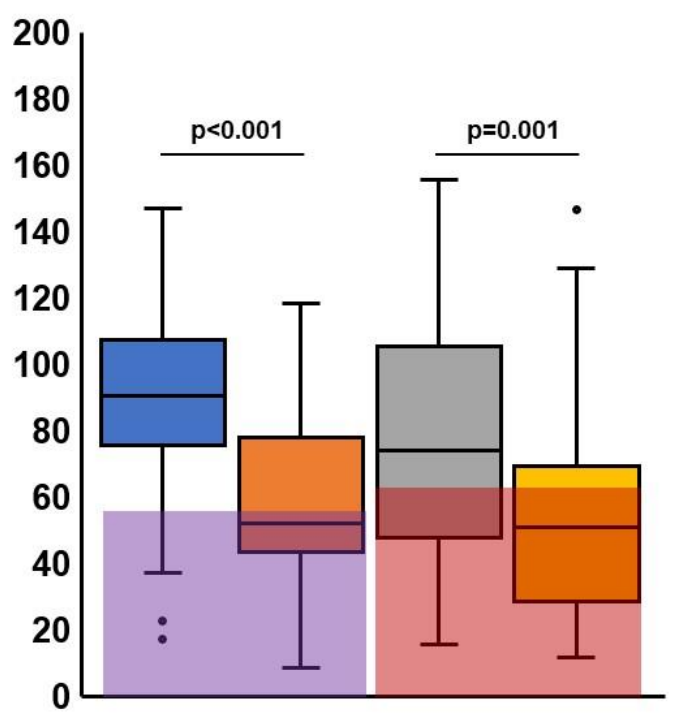

Anti-PC- Anti-PC+ Anti-PC- Anti-PC+

APCR by rhAPC APCR by Protac $\circledast$

\section{LEGEND TO FIGURE 3: APCR to exogenous APC and to activation of endogenous protein C}

by Protac ${ }^{\circledR}$ in patients with SLE stratified according to aPL profile and thrombotic history Data are presented as percentage ETP inhibition by the administration of by rhAPC and Protac $\AA$ during TGA. Overlying semi-transparent areas identify the range of ETP inhibition falling within the cut-off for APCR ( $<56 \%$ for rhAPC and $<63 \%$ for Protac $\AA$ ). A: APCR by rhAPC and Protac $\AA$ among diagnosis groups. B: patients with SLE are stratified by anti-PC profile. Patients with anti-PC had reduced ETP inhibition and higher rates of APCR by both rhAPC and Protac $\AA_{\text {. }}$ 
